\title{
Assessment of Wheelchair Technology in Tanzania
}

\author{
Amos G. Winter, V \\ PhD Student, Department of Mechanical Engineering \\ Massachusetts Institute of Technology \\ Cambridge, MA 02139 \\ awinter@mit.edu
}

\begin{abstract}
The purpose of this assessment was to determine the current state of wheelchair technology in Tanzania and the factors that prevent Tanzania's disabled from utilizing wheelchair technology. Ninety-nine interviews of wheelchair and tricycle users, wheelchair and tricycle manufacturers, and advocacy groups for the disabled were conducted throughout Tanzania during the summer of 2005. Technical issues identified included: tricycles are more popular and much less expensive than wheelchairs; most disabled people rely on donations to buy a mobility aid; production costs can be decreased by using bicycle components and outsourcing tasks; bicycle components are available in rural areas and are attractive for use in wheelchairs; and donated wheelchairs are often irresponsibly distributed and poorly designed for their operating environment. The assessment was conducted under the supervision of the Tanzania Training Center for Orthopedic Technologists and Whirlwind Wheelchair International.
\end{abstract}

Index Terms - developing countries, disability, handcycle, mobility aid, tricycle, wheelchair

\section{INTRODUCTION}

People with physical disabilities in developing countries face many challenges integrating into everyday life. If these people cannot obtain a wheelchair they are sometimes forced to stay trapped in their home or use crawling as their only means of transportation. Disability $\mathrm{KaR}^{\mathrm{i}}$, which is helping to oversee wheelchair projects in developing countries, reports that only $2 \%$ of people in Africa who need a wheelchair actually have one. The Tanzania Association of the Disabled (CHAWATA) estimates there are 30,000 people who need wheelchairs in Tanzania and only 2,000 who have one. ${ }^{\text {ii }}$ Immobility adversely affects the lives of disabled people by, for example, making it near impossible to attend school, participate in the community, or earn an income. The terrain in developing countries can further impede integration into society; in urban environments doorways and bathrooms are typically not handicapped accessible, and in rural settings roadway quality can be hilly, rough, and muddy.

Efforts have been made in Tanzania to improve wheelchair technology, fabrication, and the channels through which wheelchairs are distributed. The Wheelchair Technologists Training Course (WTTC) at the Training Center for Orthopedic Technologists (TATCOT) ${ }^{\text {iii }}$ in Moshi, developed in part by the NGO Motivation, ${ }^{\text {iv }}$ is a one-year course for a Certificate for Wheelchair Technologists. The WTTC covers manufacturing and fitting of wheelchairs designed for African countries, which can be produced in small-scale, self-sustained shops. Whirlwind Wheelchair International $(\mathrm{WWI})^{\mathrm{v}}$, a US-based non-profit NGO that develops appropriate wheelchair technology for developing countries, has helped establish 21 wheelchair manufacturing shops around the world. One of the wheelchair designs taught in the WTTC is based on a WWI model.

Although chairs are being produced in Tanzania, most people only have accessibility to imports that are poorly made, improperly fitted, and dangerous to the user. Wheelchairs need to 
be fitted with the consideration of the user's size, age, and nature of disability, among other factors. If improperly fitted, the chair can cause pressure sores - breaks in the skin produced by a person's weight pressing against an unyielding surface. These sores can develop almost immediately upon contact. If left untreated they can become infected and lead to death.

The purpose of this assessment is to elucidate the factors in current wheelchair design, manufacturing, distribution, and use that are prohibiting Tanzanian wheelchair users from accessing and utilizing appropriate wheelchair technology. Such factors can be in the form of technological inadequacies for the operating environment, inefficient manufacturing practices, lack of competitive pricing, ineffective or limited cost subsidizing, inefficient distribution practices, etc.

This document summarizes the findings of the full report written on the assessment, which is available for download $^{\mathrm{vi}}$. The assessment was supervised by TATCOT and WWI and was meant to provide feedback to both organizations to aid in future wheelchair planning strategies in Tanzania. To the knowledge of the author, TATCOT, and WWI, such an assessment has never been conducted in Tanzania. Written permission was granted from each interviewee before interviews were conducted.

\section{ASSESSMENT STRATEGY}

\section{Interview Content}

The aim of this assessment was to inspect the current state of wheelchair technology from multiple angles by interviewing the primary parties involved with wheelchair design, manufacturing, and use. Three types of questionnaires were developed by the author, in conjunction with TATCOT and WWI, to interview individual wheelchair users, wheelchair advocacy groups, and wheelchair manufacturers. In this paper the terms "wheelchair" and "tricycle" are both used to describe types of mobility aids. Common examples of these machines are shown in Figure 1.

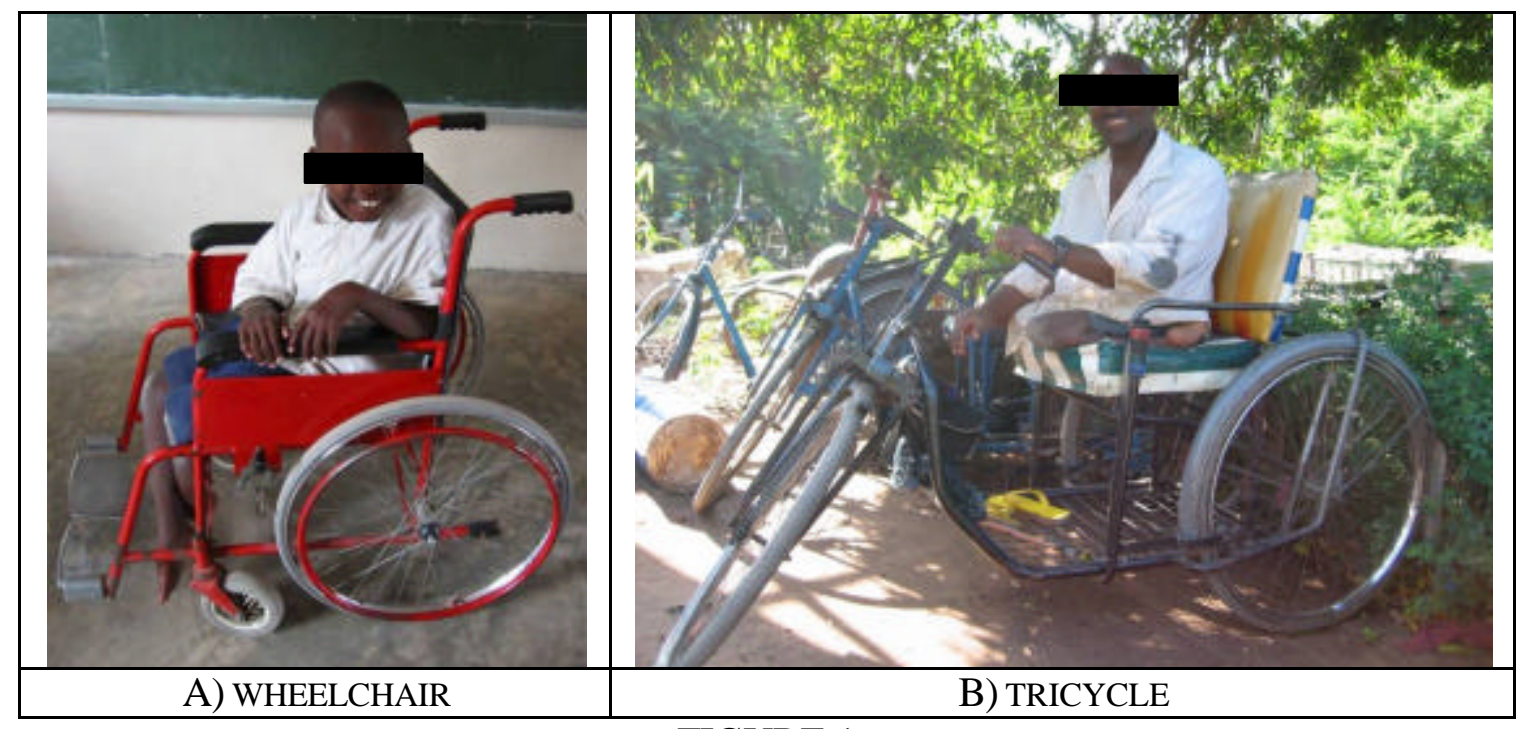

FIGURE 1

COMMON MOBILITY AIDS 
A short content summary of each party's questionnaire is below. Full versions of the questionnaires can be found in the original report ${ }^{\mathrm{vii}}$.

- Individual wheelchair/tricycle users: How was the wheelchair/tricycle obtained; who paid for the wheelchair/tricycle, who made the wheelchair/tricycle; at what age was the wheelchair/tricycle obtained; what type of mobility is the wheelchair/tricycle used for short or long travel; how functional is the wheelchair/tricycle in the users life; what types of technical problems are encountered; what caused the disability; at what age was the first and current wheelchair/tricycle obtained.

- Advocacy groups: What services are provide to wheelchair/tricycle users; does the organization purchase wheelchairs/tricycles; are they donated to the org - and if so by whom; does the org have a need-based subsidizing plan; how many people are in the org; how many wheelchairs/tricycles have been distributed; are there any technical problems observed with the members' chairs.

- Manufacturers: What types of wheelchairs/tricycles are produced; how much does each cost; what types of components are being used; what types of raw material is used; how quickly are products produced; what types of manufacturing strategies are in use; how many people are employed.

\section{Interview Locations}

Interview locations were chosen in an effort to represent both urban and rural wheelchair operating environments. The primary interview locations were Dar es Salaam, Moshi, Arusha, and Stone Town, Zanzibar. Visiting remote villages and interviewing disabled was logistically impossible. Advocacy groups working in rural areas provided most of the information about rural wheelchair use. Some rural information was contributed by urban interviewees who had lived much of their life in a village. The majority of interviews were conducted in the Dar es Salaam area because it has the highest population density and concentration of wheelchair related organizations in the country.

\section{RESULTS AND DISCUSSION OF WHEELCHAIR USER INTERVIEWS}

The following section presents critical results from wheelchair user interviews and provides discussion on issues the data reveals. The full compilation of data from the assessment can be found in the original report ${ }^{\text {viii }}$. In all, seventy-one disabled people were interviewed in the assessment.

\section{Causes of Disability}

Figure 2 shows the distribution of disability causes for the interviewees. Polio was the most common disability observed, at $38 \%$ of the interview population. Most polio survivors interviewed contracted the virus early in life. 


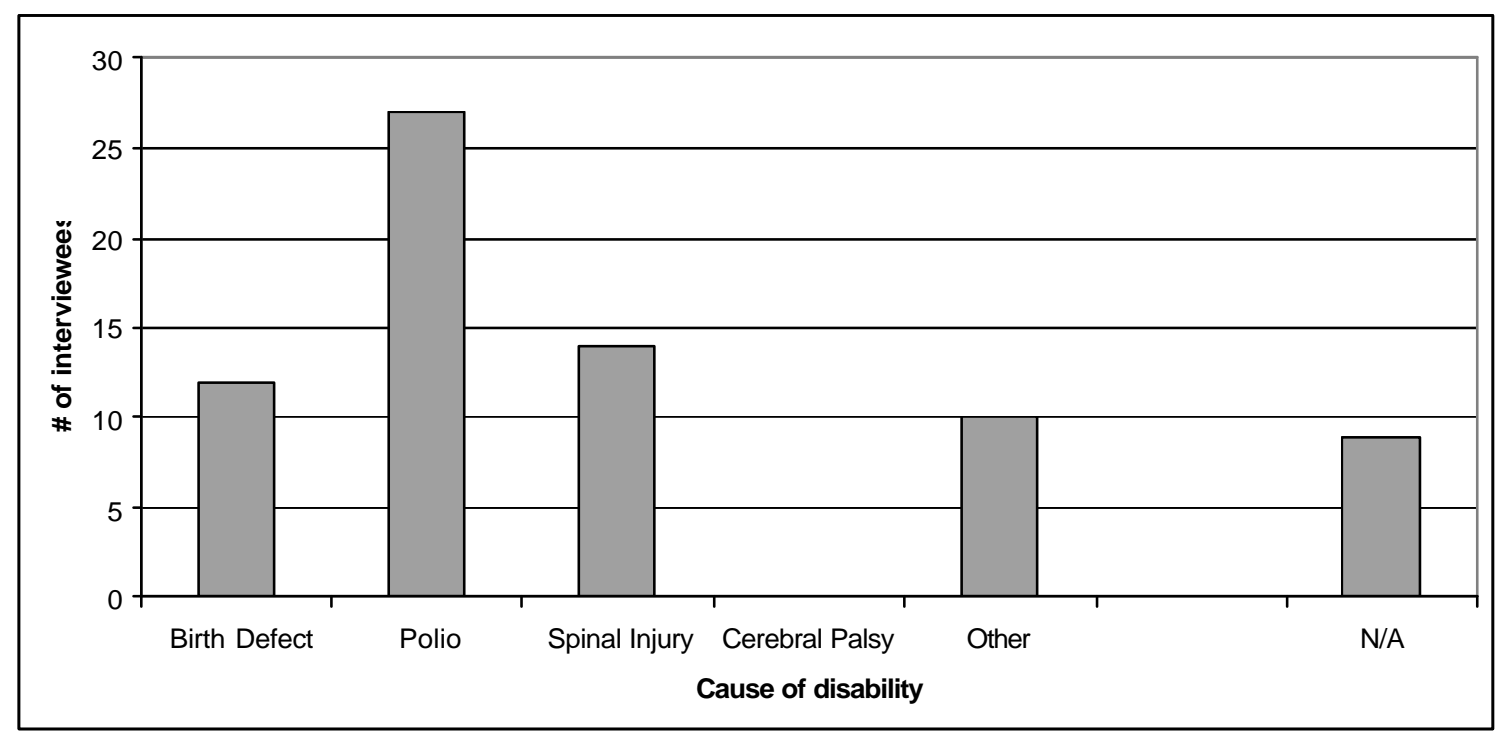

FIGURE 2

DISTRIBUTION OF INTERVIEWEE DISABILITIES

It is important to note that only people who were available or visible to the author were interviewed. Survivors of birth defects and polio made up 54\% of the interviewees. In comparison to the spinally injured, who typically became disabled later in life ( 20 years old), birth defect and polio survivors had more time to acclimate to their disability by learning to crawl or use a mobility aid. Thus, the people who were able to work or beg on the street were primarily polio or birth defect survivors and represent a larger portion of the interviewees.

\section{Pre-wheelchair Mobility}

As a result of the majority of interviewees becoming disabled early in life, most used crawling as their primary form of mobility before obtaining a wheelchair or tricycle. This trend is seen in Figure 3, with $49 \%$ of the interviewees relying on crawling before obtaining their current mobility aid. 


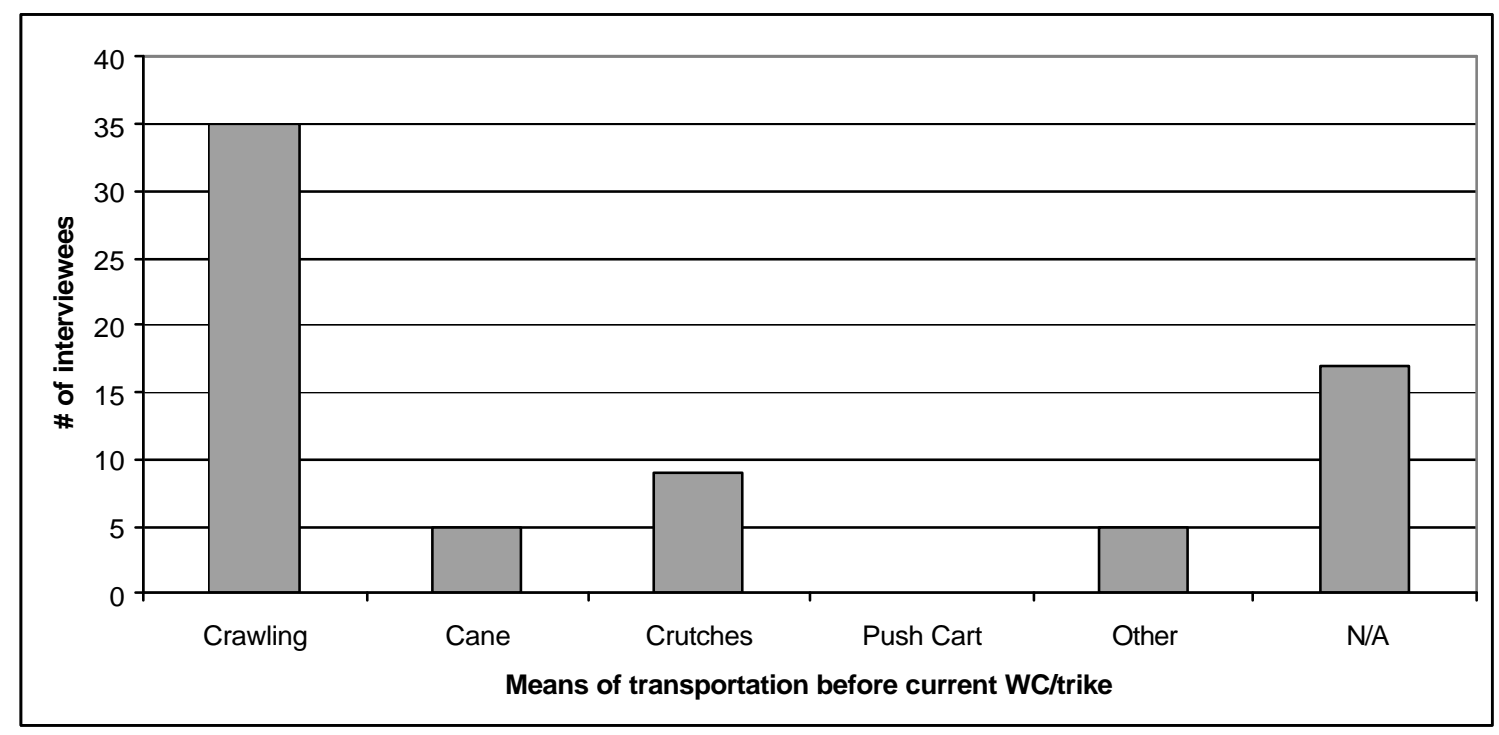

FIGURE 3

MEANS OF TRAVEL BEFORE CURRENT MOBILITY AID

Figure 4 demonstrates how long people wait before receiving a mobility aid. The average interviewee age of obtaining a first wheelchair or tricycle was 22 years old. As a result, most people who went to school or had a job before the age of 22 were forced to crawl as a primary means of travel, while others were simply unable to attend school or obtain a job because of distance.

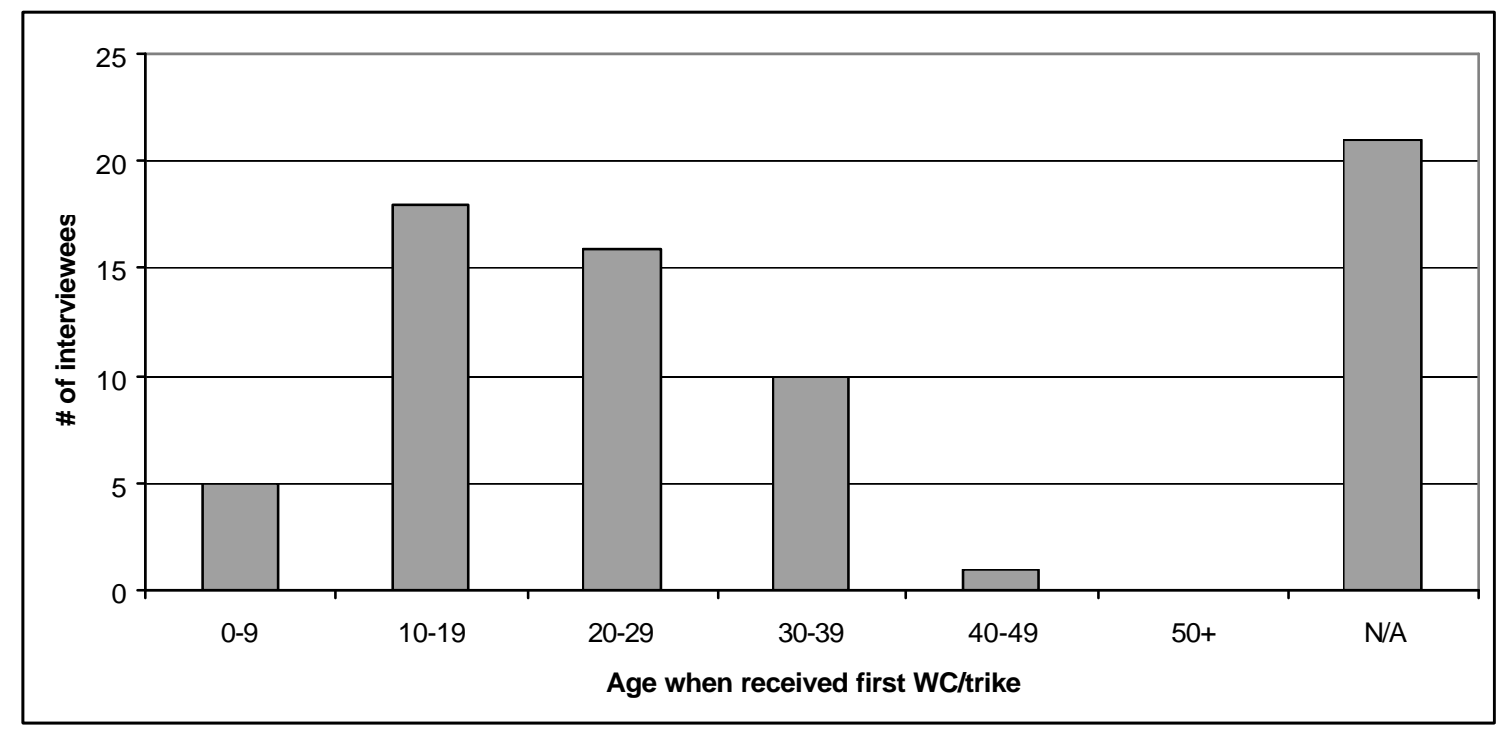

FIGURE 4

AGE WHEN FIRST MOBIUTY AID OBTAINED

Usage after Obtaining a Wheelchair or Tricycle

Figure 5 and Figure 6 indicate why tricycles are the preferred mobility aid. Most of the interviewees needed to travel multiple kilometers per day, with $36 \%$ traveling more than $5 \mathrm{~km}$ 
and many more traveling over $1 \mathrm{~km}$. For long distances, a tricycle requires much less energy than a wheelchair. Although Figure 6 shows only slightly more tricycle users than wheelchair users, it is important to note that the author had to make a concerted effort to find wheelchair users, but had to forgo many interviews with tricycle users. On the street, it was much more common to see a tricycle user. Wheelchair users were only interviewed in hospitals, schools, and rehabilitation centers - places that required small distances of movement per day. During the duration of the assessment not a single wheelchair user was seen outside an enclosed facility or organization.

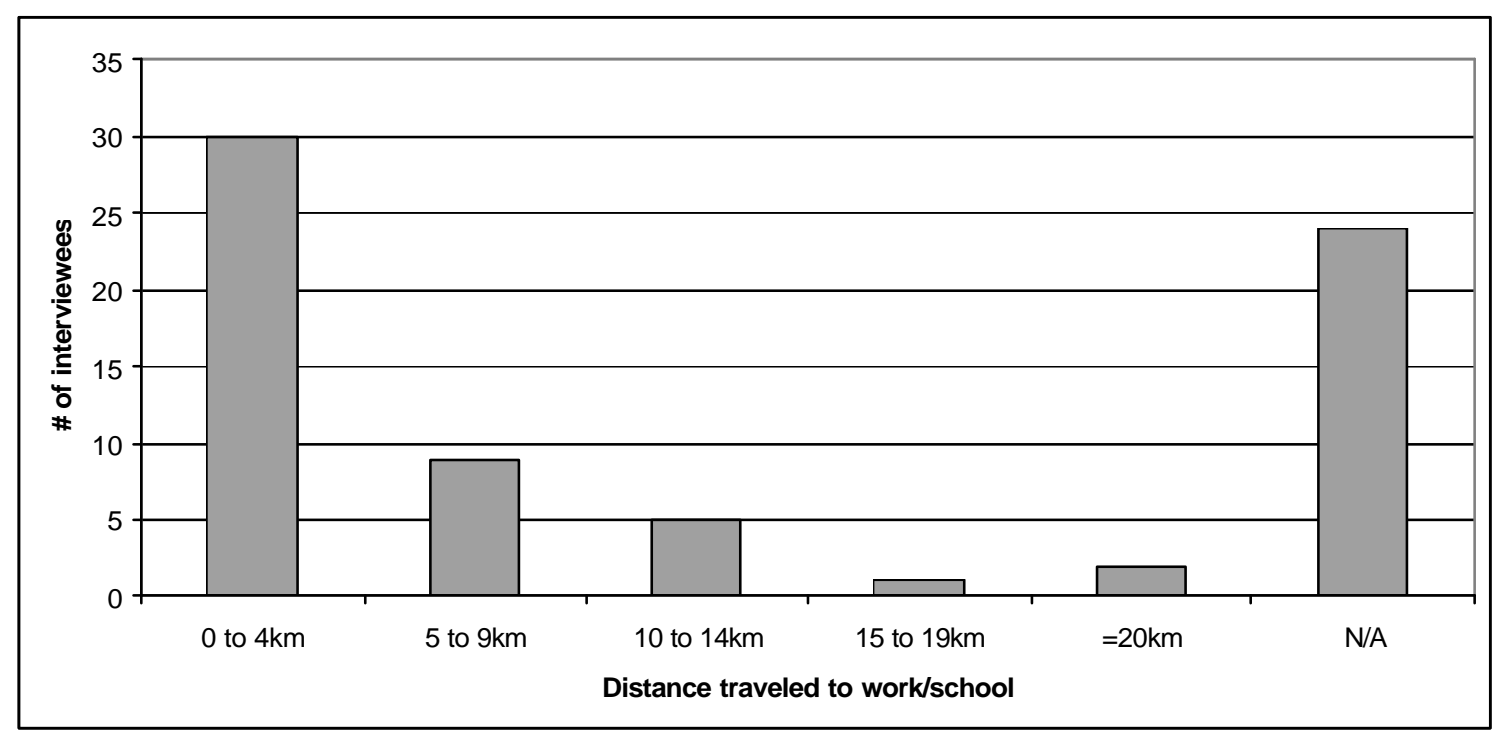

FIGURE 5

DAILY TRAVEL DISTANCE OF INTERVIEWEES

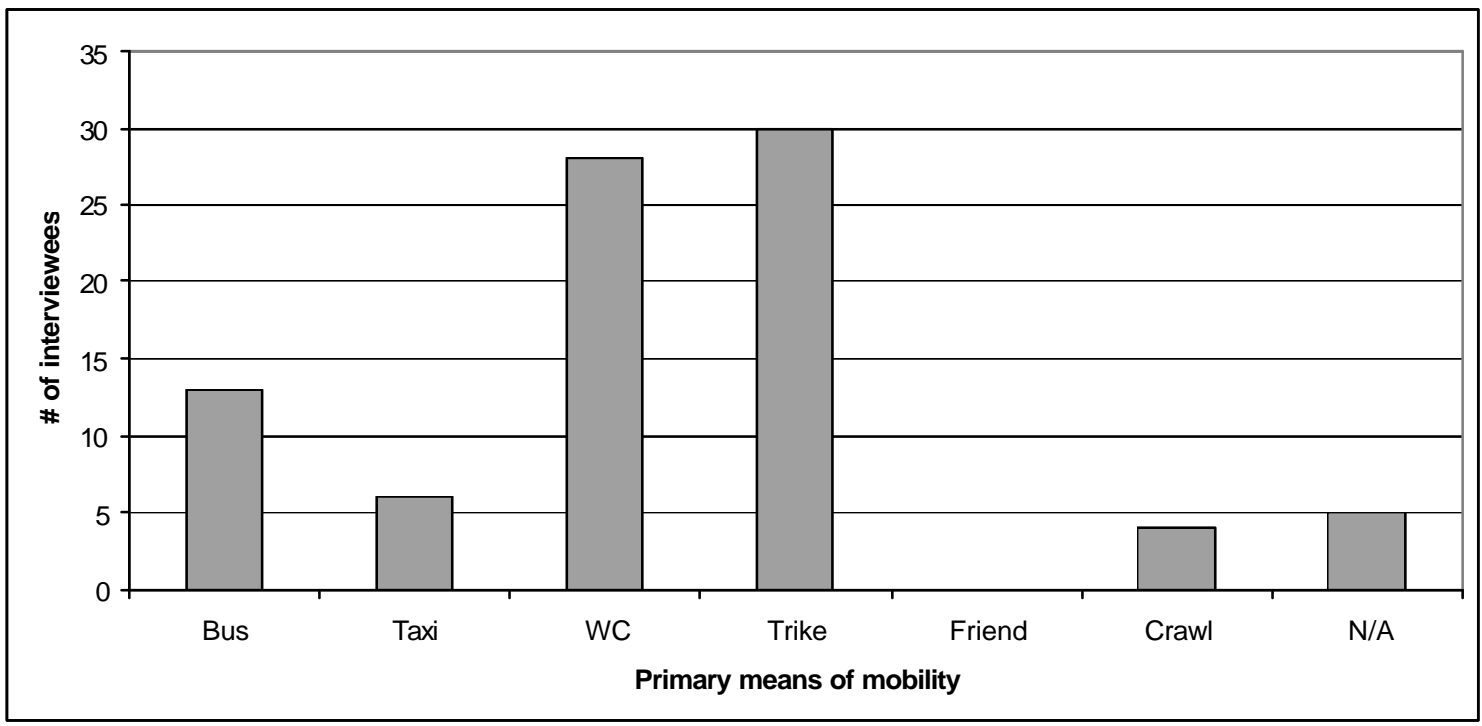

FIGURE 6

MEANS OF TRANSPORTATION USED 
The preference of tricycles by Tanzanian disabled can be further explained by comparing Figure 5 and Figure 6 with Figure 3 and Figure 4. Figure 4 shows that most people interviewed did not get a mobility aid until later in life (mean age of 22), and Figure 3 shows many had been forced to crawl small distances. As a result, there is a greater need for many disabled to travel long distances using a mobility aid, such as going from home to work. Since many of the interviewees were capable of crawling short distances, they were willing to forgo the short-range mobility offered by a wheelchair for the multiple-kilometer capabilities of a tricycle. Furthermore, local busses rarely permit disabled people to ride; many interviewees commented on being turned away when trying to ride a bus. The author used city busses as his primary mode of transportation throughout the study and did not once see a wheelchair or tricycle user as a passenger.

Imported wheelchairs were much more common than ones made in-country, with $73 \%$ of wheelchair users having a chair made abroad. Only two interviewees used Tanzania-made wheelchairs as their primary mobility aid. The majority of imported wheelchairs observed came from the Wheelchair Foundation ${ }^{\mathrm{ix}}$, which has given thousands of chairs to Tanzania over the past decade.

\section{Wheelchair and Tricycle Purchasing}

A problem observed during the assessment was the inability of people to purchase their own mobility aid. Figure 7 shows the distribution of income of the interviewees. The average monthly income was \$49US, which is twice Tanzania's national average income of \$24 per month. ${ }^{\mathrm{x}}$ This discrepancy can be attributed to the following factors: 1) People with jobs were easier to find and interview; 2) Most of the interviews were conducted in urban areas where there are more formal and informal income-generating opportunities and higher average incomes; 3) Only $35 \%$ of the national population is urbanized. ${ }^{\mathrm{xi}}$

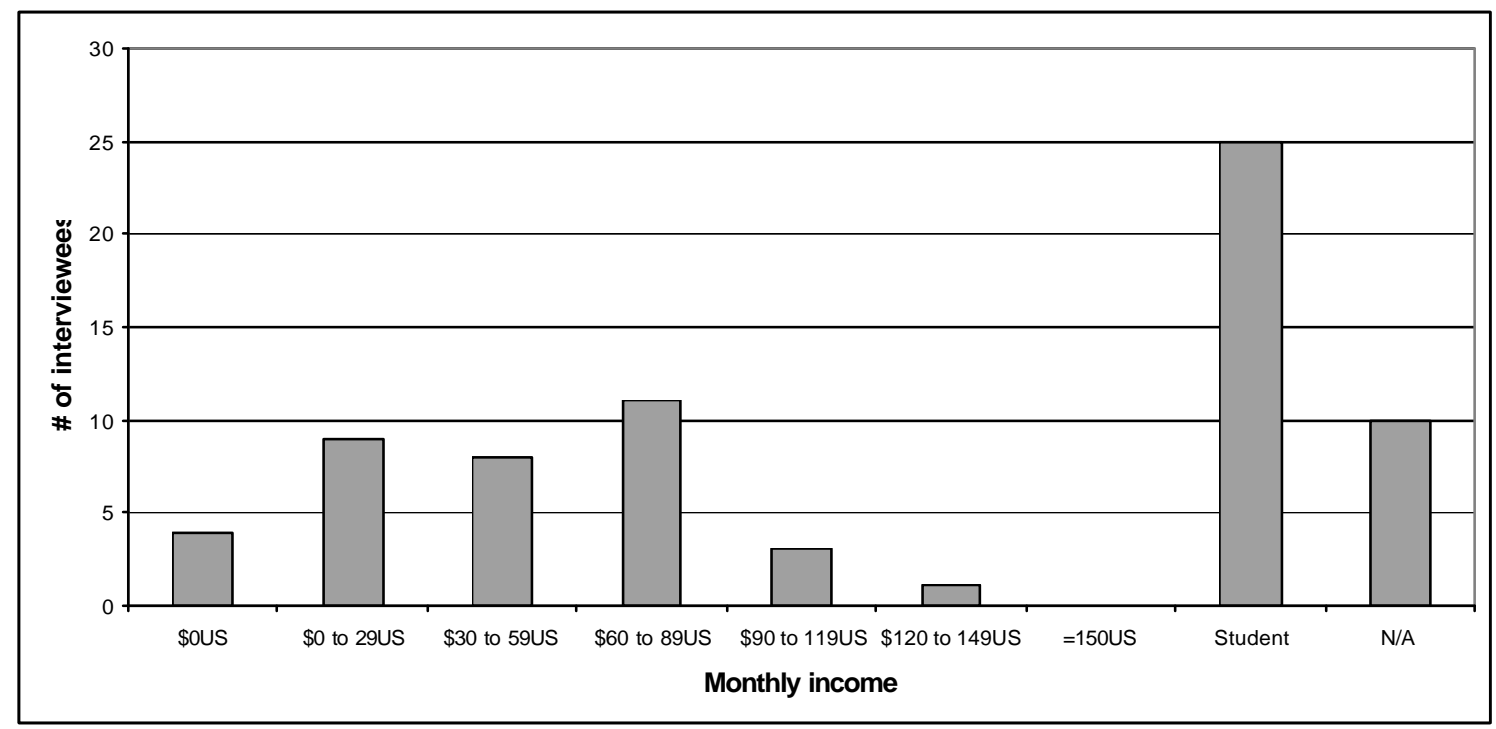

FIGURE 7

INCOME OF INTERVIEWEES

Figure 8 shows the large price gap between the cost of a new mobility aid and what users can afford. The majority of people interviewed, $67 \%$, had wheelchairs or tricycles that cost between 
\$100US and \$200US, but $90 \%$ of the people who answered the question said they could only contribute \$0US to \$50US for a new chair or tricycle. This leaves approximately a \$100US gap between what people can afford and what mobility aids cost. The majority of interviewees, 78\%, did not contribute any money towards their current mobility aid. Figure 9 demonstrates how dependent disabled people are on contributions from others to purchase a wheelchair or tricycle. Only $14 \%$ of those interviewed were able to purchase their own mobility aid.

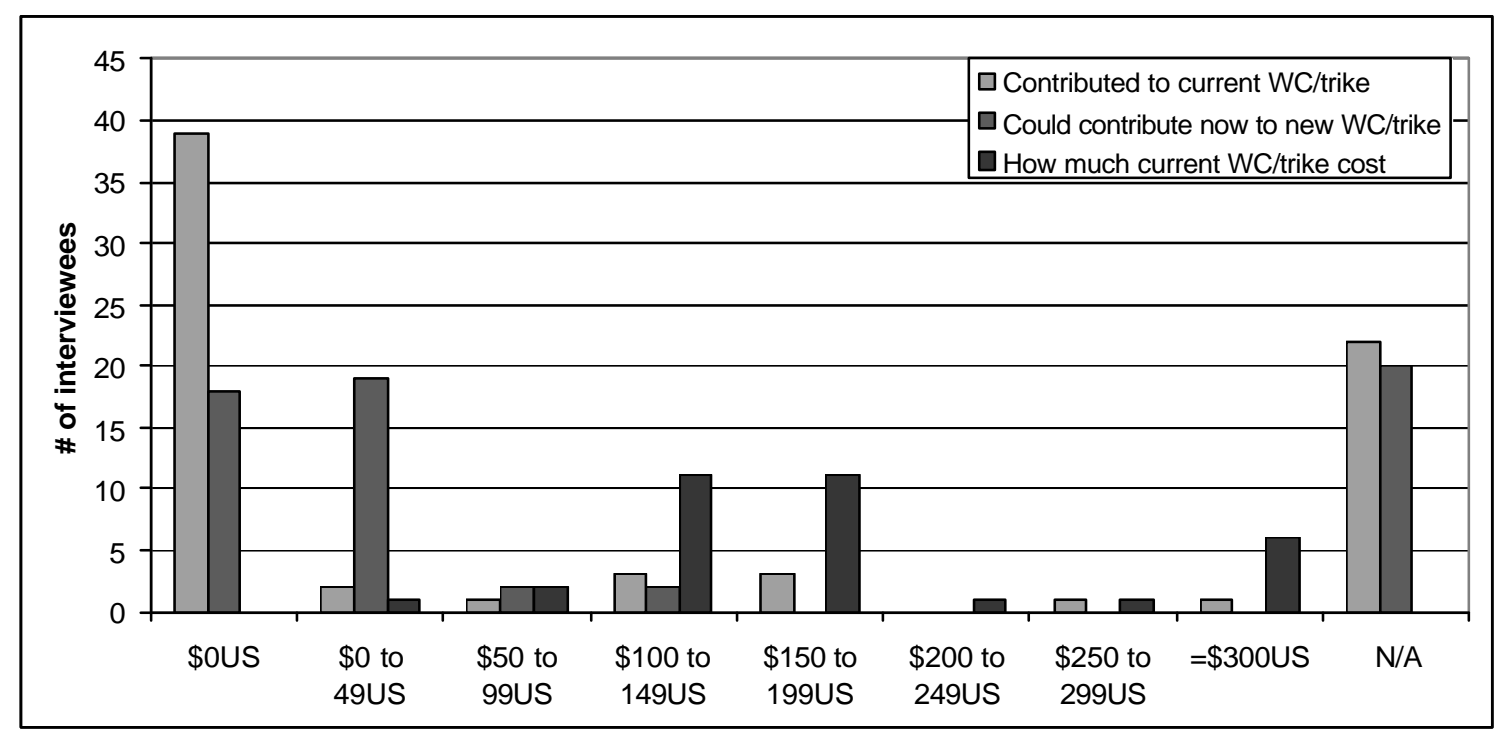

FIGURE 8

PRICE GAP BETWEEN WHEELCHAIR/TRICYCLE COST AND WHAT USER CAN AFFORD

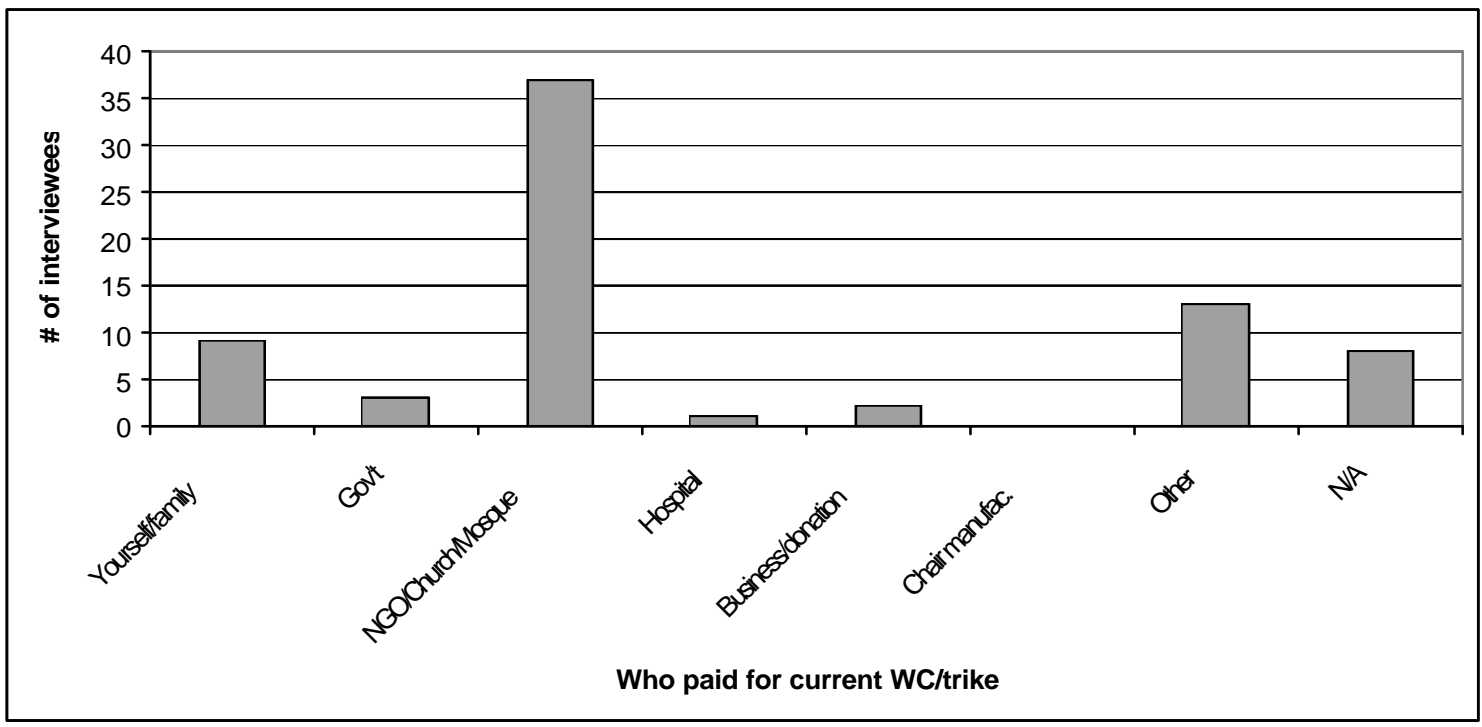

FIGURE 9

SOURCES OF FUNDS FOR CURRENT MOBILITY AID 


\section{Locations of Wheelchair Repair}

Bicycle shops were the most common location of wheelchair and tricycle repair reported during the assessment, as shown in Figure 10. In the category of "Other," 14 of the 17 responses were from children at the Salvation Army Rehabilitation Center ${ }^{\text {xii }}$ who get their wheelchairs repaired at the on-site workshop. The majority of those children said they have their chairs repaired at bicycle shops when they are at home. The most common complaint about foreign wheelchairs was that spare parts are not available. Tricycles are easily repaired at bicycle shops because they are primarily built from bicycle parts.

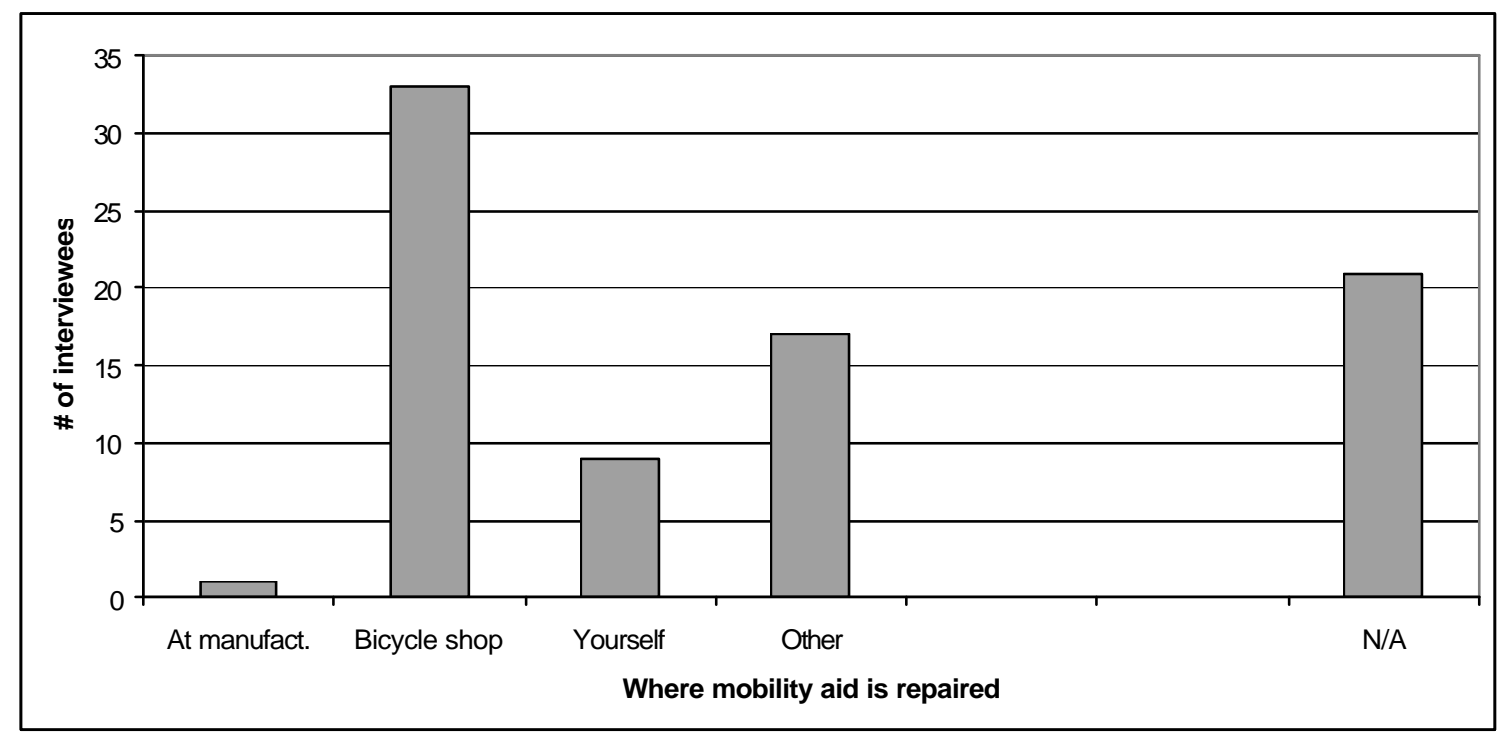

FIGURE 10

DISTRIBUTION OF REPAIR LOCATIONS

\section{RESULTS AND DISCUSSION OF MANUFACTURER INTERVIEWS}

\section{Products of Manufacturers}

Table 1 reports the wheelchairs and tricycles being produced by the eight Tanzanian manufactures interviewed during the assessment. Contact information for all the manufactures is included within the original report ${ }^{\mathrm{xiii}}$. 
TABLE 1

WHEELCHAIRS AND TRICYCLES CURRENTLY PRODUCED IN TANZANIA

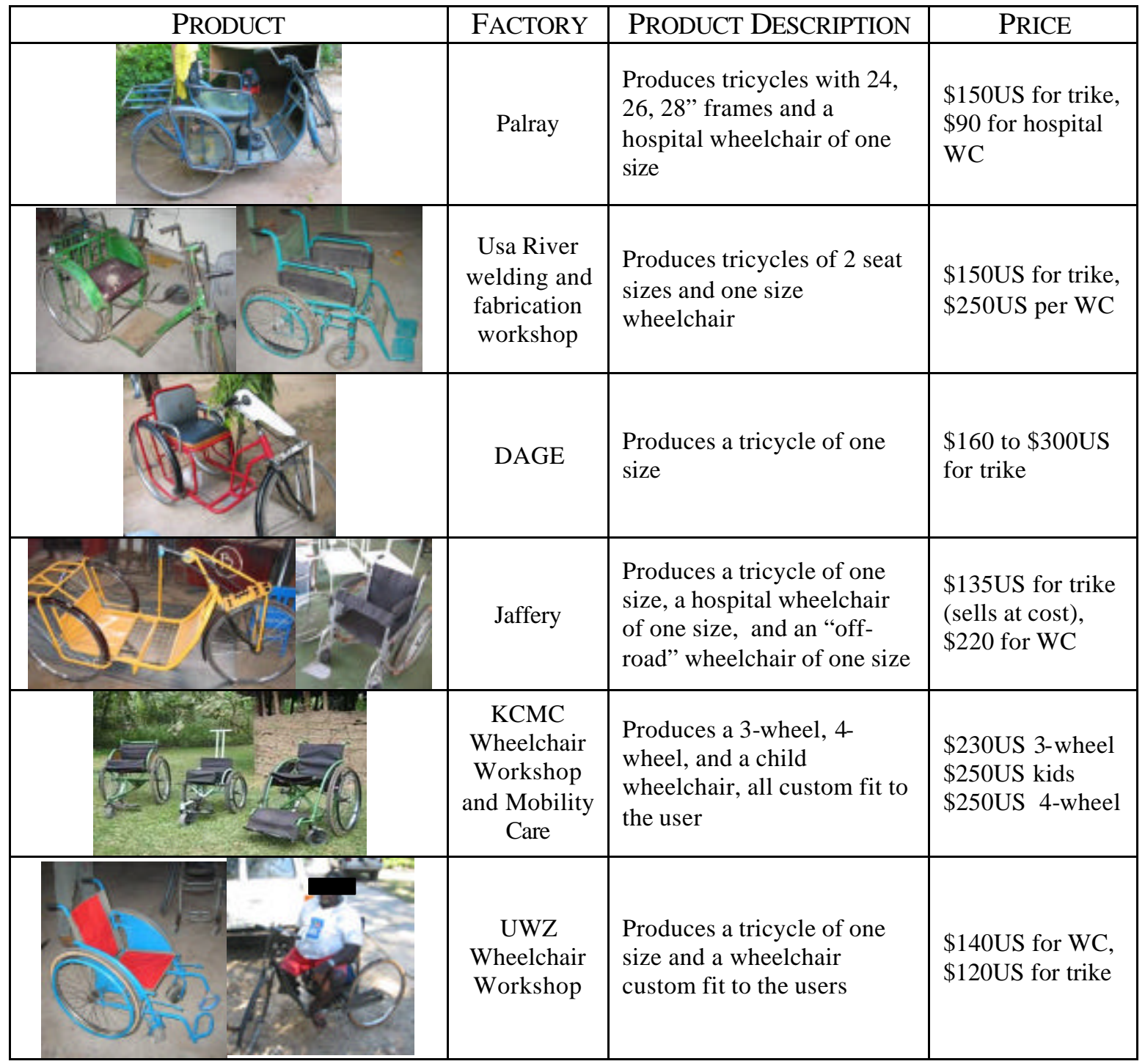

\section{Price Comparison}

Table 1 shows that tricycles cost approximately \$100US less than the wheelchairs. This most likely contributes to the greater popularity of tricycles over wheelchairs in Tanzania. In order to be competitive, Tanzanian wheelchair manufacturers should lower their prices to the level of tricycles and imported chairs. Price reduction is possible, considering the UWZ workshop is able to sell a wheelchair for \$140US that is essentially identical to the Mobility Care 4-wheeler sold at $\$ 250$.

Upon inspection of tricycle manufacturing facilities, the following factors were observed to contribute to low production costs. 
- Minimized individual part production: Palray produces only the frames of the tricycles they build. All other parts are purchased. This practice greatly decreases production time and the variety of tasks workers are required to complete.

- Maximum usage of bicycle parts: Other than the frames, all other parts in a Palray tricycle are from bicycles. Many of the parts are produced in China at a much lower cost than what they could be made for in Tanzania.

- Assembly line production: All of the tricycle shops used an assembly line, with dedicated people in charge of one or only a few production steps. The work is more repetitive in an assembly line, but time for switching setups and tasks is reduced.

- Incentive-based payment: Jaffery uses commission based salary to promote competition between employees producing the same parts, increasing productivity.

\section{Inadequate Mechanical Design}

This section discusses mechanical design problems that prohibit wheelchairs and tricycles being produced in Tanzania from performing adequately.

\section{Axle Bending}

The axles used in the WTTC 4-wheeler are too weak. There are loading conditions where the axle might bend, one of which is represented by Figure 11 where the full load of the user is exerted on one of the rear wheels while the chair is tipping. A situation where this loading condition could occur is when a friend is pushing a wheelchair user off a curb on the rear wheels and one wheel drops before the other. The dimensions in Figure 11 were taken from a WTTC 4wheeler and the load is a $670 \mathrm{~N}$ (150lbs) person.

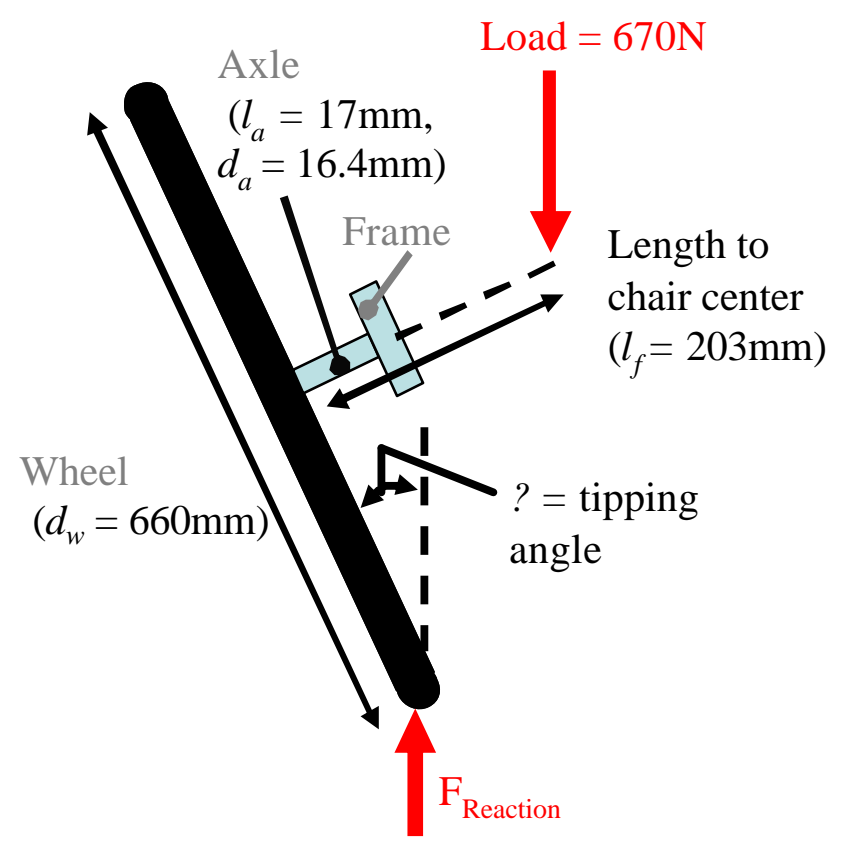

FIGURE 11

TIPPING OF WTTC 4-WHEELER 
The bending stress on the axle is a function of the load and tipping angle, and is expressed in Equation 1.

$\sigma=\frac{1.55 N}{m m^{3}}[(330 \mathrm{~mm}) \sin \theta-(52 \mathrm{~mm}) \cos \theta]$

\section{EQUATION 1}

The tip-over point of the chair is approximately 31 degrees, where the center of mass is vertically aligned over the reaction point of the wheel and the ground. If the frame is made of mild steel, with a yield stress of $330 \mathrm{~N} / \mathrm{mm}^{2}$, the max bending stress at that angle is $59 \%$ of the yield strength of the steel. Note that this analysis is static. If a chair were to drop off a curb only a few inches, the shock load could be multiple times greater and cause the axle to yield. One should also consider that the highest stress occurs at the point where the axle is welded to the frame, where the material will be weaker due to the weldment.

\section{Weakness of X-brace Center Pivot}

A number of workshops reported that the holes that hold the bolt for the center pivot of the $\mathrm{X}$ brace would quickly wear out and open up, decreasing the rigidity of the brace. The widening of the brace hole is the result of high torques being exerted on the pivot pin when the chair is on 3 wheels, such as when rolling over rough ground. A 4-wheeled chair is probably not the best solution for very bumpy operating environments. Unless the frame has a lot of compliance or slack in the joints, only 3 wheels will touch the ground.

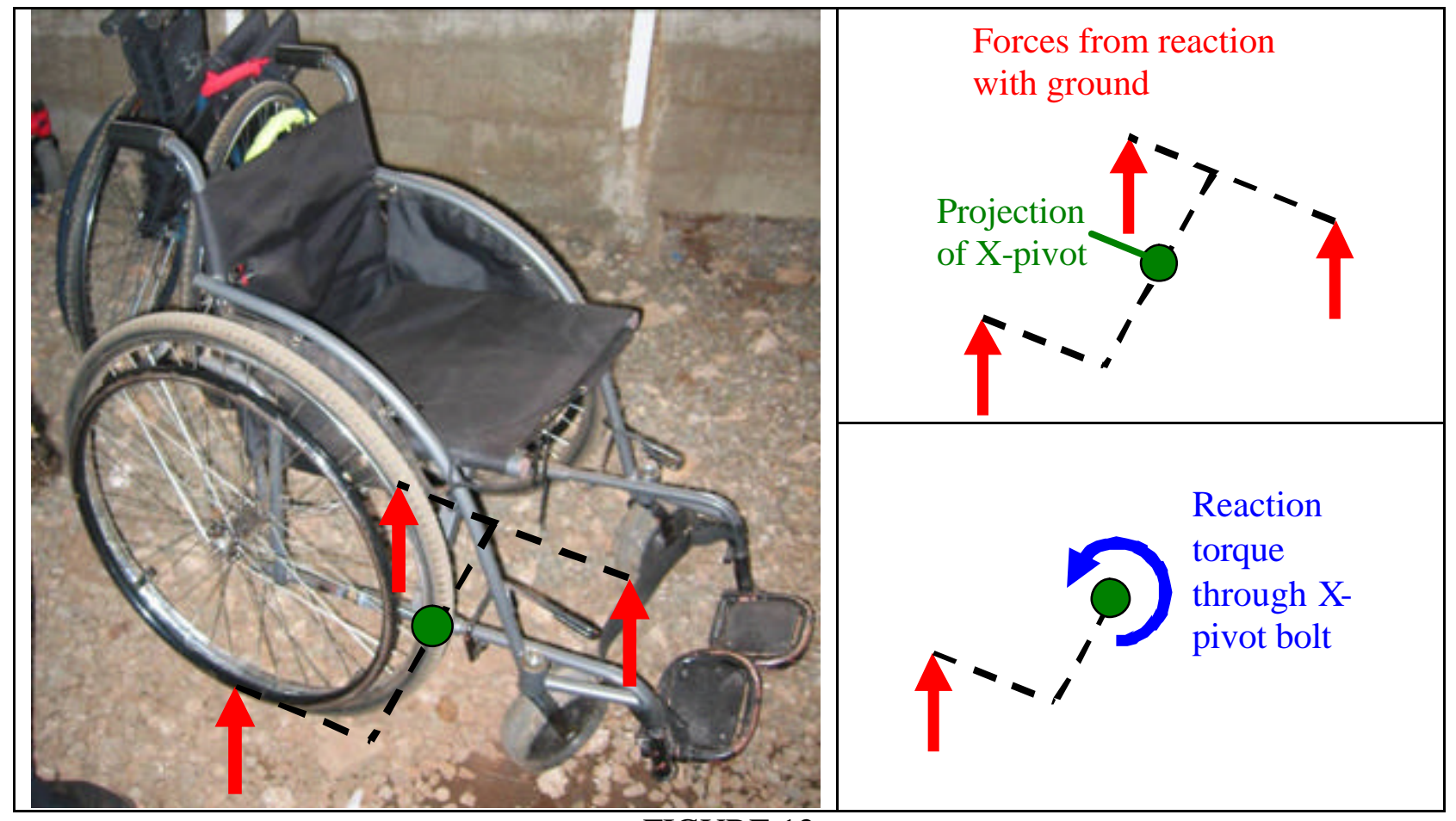

FIGURE 12

PROJECTION OF MOMENTS IN X-BRACE OF WTTC 4-WHEELER 
Some of the manufacturers said that fixed-frame 3-wheeled chairs are preferred by people who have to travel on rough terrain, as the chair is always kinematically constrained with the ground. One of these manufacturers said that the 4-wheeled WTTC chair is primarily sold to hospitals, where the ground is even and flat. This is unfortunate, as the WTTC 4-wheeler was originally intended for rough terrain.

\section{Tricycle Frame Weakness}

Many of the tricycles observed had bent frames, or had frames that had been bent in the past and since repaired. The frame weakness is the result of designing the second moment of area too low in the center of the frame. This problem was observed in the Palray, Jaffery, and DAGE frames. A bucked frame and corresponding moment within the frame are shown in Figure 13. Bending stress is proportional to the applied moment, the distance from the neutral axis, and the inverse of the second moment of area. Thus the highest stress occurs at center of all the Tanzanian tricycle frames.
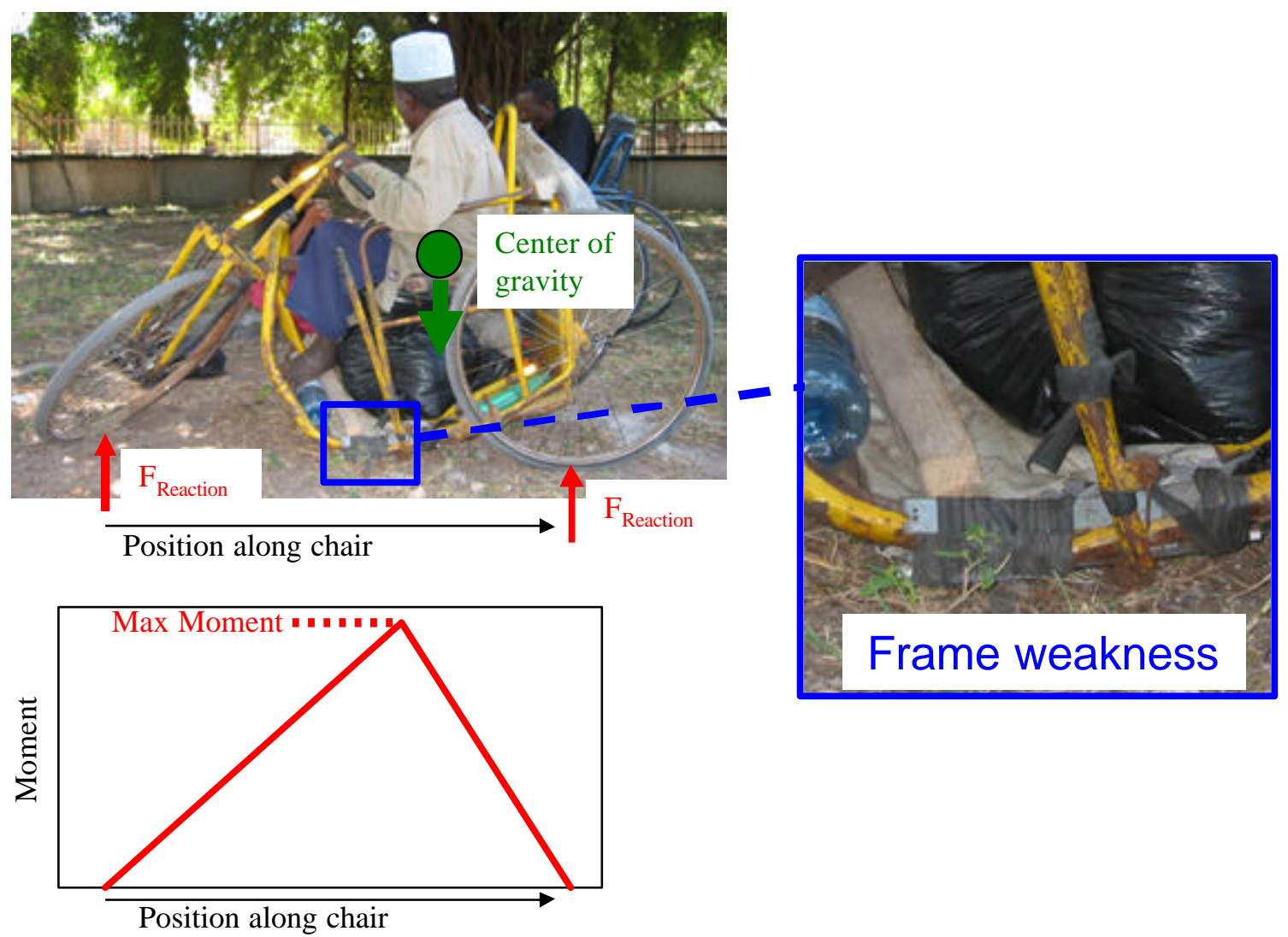

FIGURE 13

BUCKLED FRAME OF A PALRAY TRICYCLE AND CORRESPONDING BENDING MOMENT

\section{Inefficient Gearing in Tricycles}

Many tricycle users observed traveling seemed to be working much harder than necessary, and during interviews many said that pedaling caused pain in their chest muscles. After riding a tricycle and experiencing the difficulties first hand, it was clear that the gear ratio was not well matched for human force and power capabilities. Figure 14 shows the gear ratio schematics of 
two tricycle designs, with each critical element characterized by its diameter. Figure 14A shows a Canadian tricycle that has a high mechanical advantage, and Figure 14B shows a DAGE tricycle that takes much more force to move.

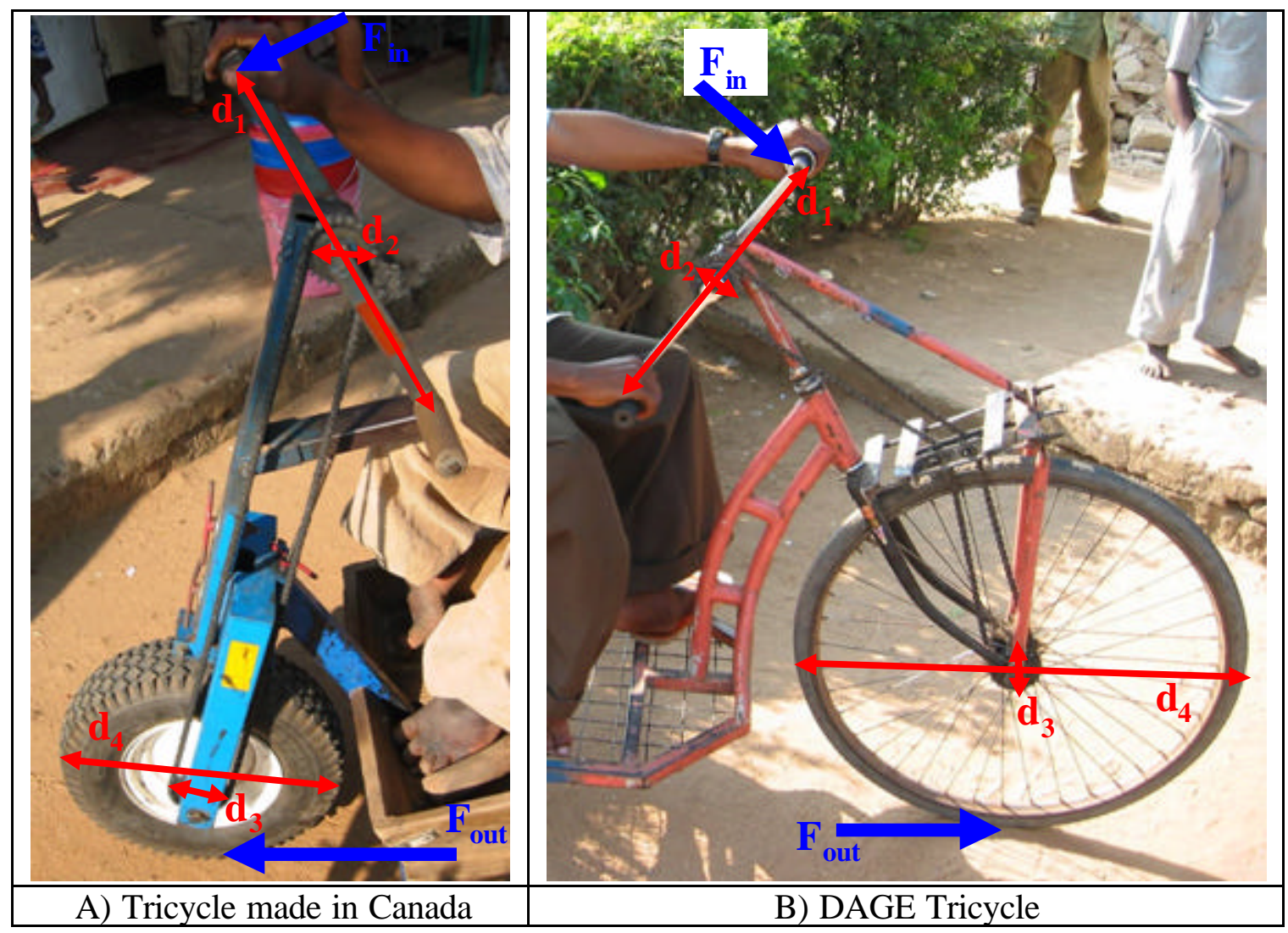

FIGURE 14

GEAR RATIOS OF TRICYCLES

Using the dimensions of Figure 14, the relationship between the force required by the user, $F_{\text {in }}$, and the output force used to move the chair, $\mathrm{F}_{\text {out }}$, is expressed in Equation 2. The DAGE tricycle produces a much lower $F_{\text {out }}$ for a given $F_{\text {in }}$ than the Canada tricycle, requiring the DAGE user to exert himself much more.

$$
F_{\text {out }}=F_{\text {in }} \frac{d_{1}}{d_{2}} \frac{d_{3}}{d_{4}}
$$

EQUATION 2

\section{Over-constrained Bearings}

All of the radial bearings in the WTTC designs are mounted in an over-constrained configuration, including the radial bearings in the caster barrel, shown in Figure 15A. Overconstraining the bearings can greatly decrease their life by inducing high stresses on the balls and races. In Figure 15B one can imagine that if the bearing spacer is too short, the inner race will not hit the spacer. The preload force from the nut will then be transferred through the bearing balls into the outer race. If the nut is tightened further, increasing the preload force, the balls and 
races will be sheared, damaging the bearings. Radial bearings are not designed to take high axial loads. If the bearing spacer is too long then the bearings will be under-constrained, allowing the fork to slide up and down.

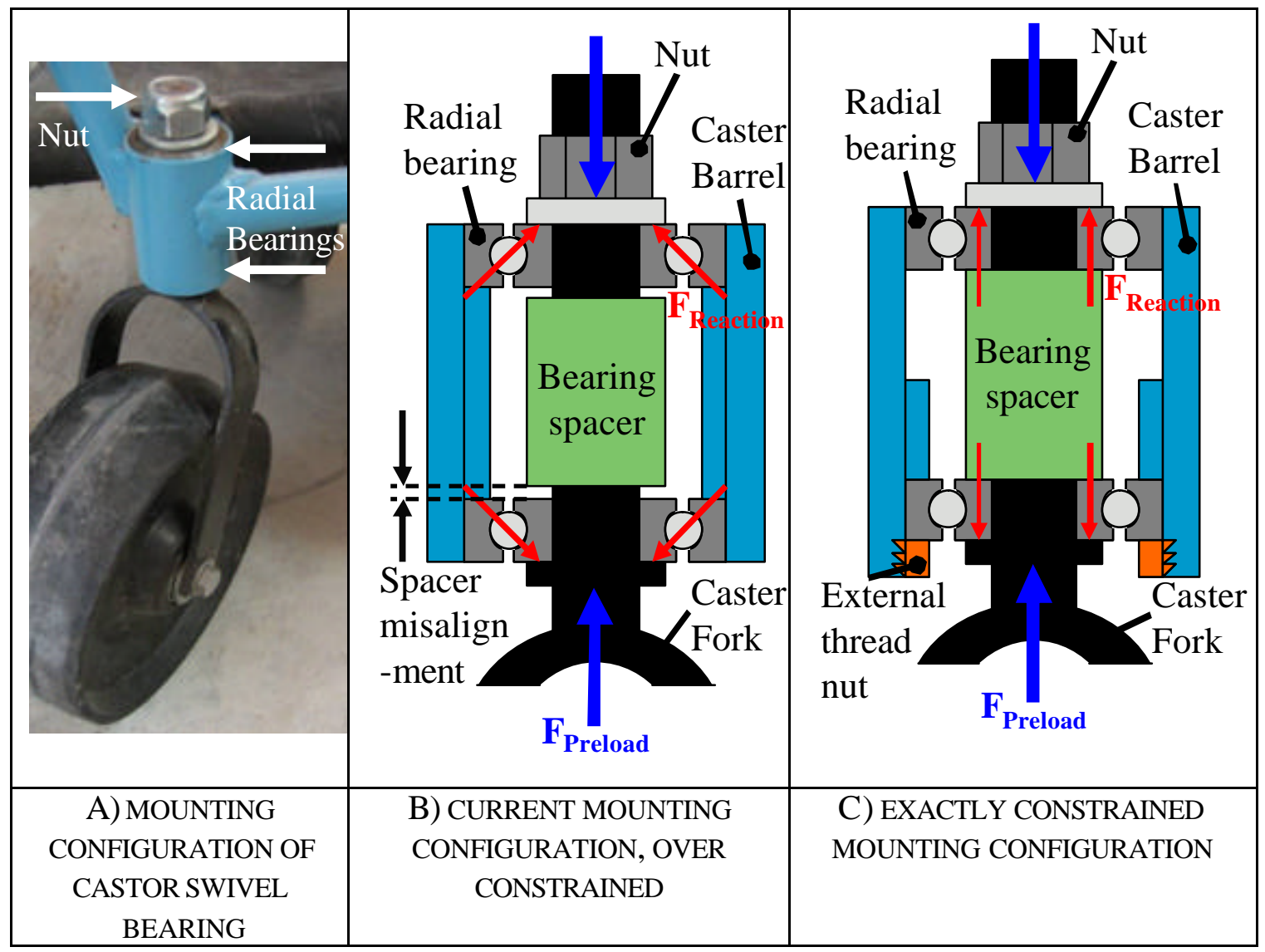

FIGURE 15

MOUNTING OF CASTER BEARINGS

For comparison, Figure $15 \mathrm{C}$ shows a mounting configuration that exactly constrains the bearings. Tightening of the nut will not damage the bearings, as the preload force will be transferred through the external faces of the inner races, which are designed to be compressed. The bearings will not slide up and down because the external thread nut will exactly position the bottom bearing, and the upper bearing will be clamped between the spacer and the nut.

It is important to note that any configuration of radial bearings used in the castor swivel is undesirable, as radial bearings are not meant to support axial loads. Loading them axially can greatly shorten their life. The proper configuration would be to use either two angular contact bearings, like what is used in bicycle hubs, or one radial and one thrust bearing, like what is sometimes used in bicycle stems. 


\section{Available Materials/Components}

A wide selection of steel and bicycle components is available in Tanzania. The country's largest steel supplier, Doshi Hardware ${ }^{\text {xiv }}$, was visited and their product line is included in the full report $^{\mathrm{xv}}$. They carry a large range of low-carbon steel stock in many cross-sections. A bicycle component supplier, Burhani Cycle Mart ${ }^{\mathrm{xvi}}$, was also visited during the assessment. Burhani provides almost every bicycle component available, including frame joints to be brazed.

\section{RESULTS AND DISCUSSION OF ADVOCACY GROUP INTERVIEWS}

During the study 18 advocacy groups were interviewed. Their contact information can be found in the full report ${ }^{\text {xvii }}$. Important information from the advocacy group interviews is summarized below.

- Few organizations are able to purchase chairs, but international NGOs in Europe or the US sometimes subsidize purchases.

- The Wheelchair Foundation ${ }^{\mathrm{xviii}}$ (WF) has given away nearly 8,000 wheelchairs ${ }^{\mathrm{xix}, \mathrm{xx}}$ in Tanzania since 2000, but it does not use appropriate technology, fitting, or distribution practices. Three other NGOs ${ }^{\mathrm{xxi}, \mathrm{xxii}, \mathrm{xxiii}}$ in the same area as WF's largest distributor are in desperate need of wheelchairs but do not receive regular donations.

- The cost of wheelchairs produced in-country has to be reduced if they are to compete with WF chairs. The price of a WF chair is $\$ 150 \mathrm{US}$. Half of that price is paid by the WF, and the other half is paid by donors. If wheelchairs being produced in Tanzania were sold at or near $\$ 150 \mathrm{US}$, they could better compete with the WF. Competitively pricing could also possibly convince WF to buy locally and support the local economy as well as the disabled.

- All organizations interviewed agreed that they did not like the imported wheelchairs because replacement parts can not be obtained. They all thought using bicycle parts was a good alternative because even in the most remote villages there is usually a bicycle repair shop with replacement parts.

\section{CONCLUSION}

The purpose of this report was to gain insight into the factors that are preventing Tanzania's disabled from utilizing wheelchair technology. Three types of interviews were conducted during the assessment, one for each group involved with wheelchair technology: wheelchair and tricycle users; wheelchair and tricycle manufacturers; and advocacy groups for the disabled. The most critical points in the responses of each group are summarized below:

- Wheelchair and tricycle users: Tricycles are the preferred mobility aid because they offer long-distance travel capability at a lower price compared to wheelchairs. Most people rely on NGOs and other organizations to purchase mobility aids, and the majority of wheelchairs being used are imported. Bicycle shops are the most common place to get wheelchairs and tricycles repaired.

- Wheelchair manufacturers: The WTTC wheelchairs cost \$100US more than tricycles produced in Tanzania. The UWZ wheelchair workshop is able to make a wheelchair essentially identical to the WTTC 4-wheeler and sell it for \$140, which is \$100US less 
than the WTTC workshops. Utilizing bicycle components and outsourcing lowers production costs. The manufacturing processes of local wheelchair manufactures could be streamlined by using lean manufacturing techniques. Wheelchairs and tricycles being produced in Tanzania have design weaknesses and should be reviewed to improve strength and robustness.

- Advocacy groups: Few organizations can afford to buy chairs, although some rely on international NGOs as sponsors. The WF donates an immense number of wheelchairs annually but without responsible distribution practices and full consideration of appropriate technology. Tanzanian wheelchairs should be priced to compete with the WF. The use of bicycle parts in wheelchairs and tricycles designed for rural areas is appropriate because bicycle technicians and replacement parts are available throughout the country.

The information gathered in the assessment was meant to aid TATCOT and WWI in planning strategies for future wheelchair technology improvements in Tanzania. Ideally the report will aid TATCOT in improving the WTTC course and WWI in designing improved wheelchairs in the future.

\section{ACKNOWLEDGEMENT}

The assessment was made possible through the financial support of the MIT Public Service Center and summer fellowship directors Sally Susnowitz and Alison Hynd. The author would like to thank his supervisors on the project, Harold Shangali from TATCOT and Marc Krizack from WWI, and his translator Joseline Mammba. The author is also grateful to Anne Healy for arranging contacts with NGOs in Tanzania and Mr. Yona Ezekiel and Mr. Emmanuel Mosha at TATCOT for their help and advice.

\section{REFERENCES}

\footnotetext{
'Wheelchair Technologists' Training Course. Disability KaR. www.disabilitykar.net (Accessed June 10, 2005)

ii Conversations with Bo Svensson, Tanzania Association of the Disabled - CHAWATA, Burguruni Juu Sokoni Street, P.O. Box 2361, Dar es Salaam, TZ.

iii Tanzania Training Center for Orthopedic Technologists. Kilimanjaro Christian Medical College. http://www.kcmc.ac.tz/TATCOT/ (Accessed A pril 20, 2005)

${ }^{\text {iv }}$ Homepage. Motivation - the international disability charity. http://www.motivation.org.uk/ (Accessed May 10, 2005)

v Homepage. 2004. Whirlwind Wheelchair International. http://www.whirlwindwheelchair.org/ (Accessed April 18, 2005)

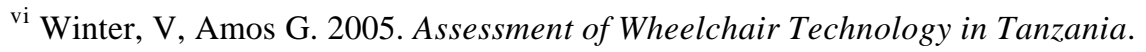
http://web.mit.edu/awinter/Public/Assesment\%20of\%20TZ\%20WC\%20technology\%20-\%20final.pdf (Accessed June 4, 2006)

${ }^{\text {vii }}$ Winter, Assessment of Wheelchair Technology in Tanzania.

${ }^{\text {viii }}$ Winter, Assessment of Wheelchair Technology in Tanzania.
} 
${ }^{\text {ix }}$ Homepage. 2006. The Wheelchair Foundation. http://www.wheelchairfoundation.org/ (Accessed June 4, 2006)

${ }^{x}$ Statistics on Tanzania. 2003. UNICEF. http://www.unicef.org/infobycountry/tanzania_statistics.html (Accessed August 10, 2005)

${ }^{\mathrm{xi}}$ Statistics on Tanzania. UNICEF.

${ }^{\text {xii }}$ Conversations with Hugoline Tillya, Salvation Army Rehab Center, P.O. Box 1273, Dar es Salaam, TZ.

${ }^{\text {xiii }}$ Winter, Assessment of Wheelchair Technology in Tanzania.

${ }^{\text {xiv }}$ Conversations with Mr. Milaro, Director, Doshi Hardware, P.O. Box 438, Dar es Salaam, TZ.

${ }^{\mathrm{xv}}$ Winter, Assessment of Wheelchair Technology in Tanzania.

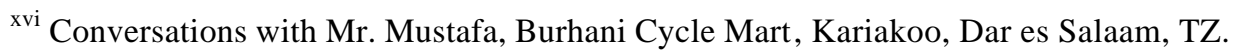

${ }^{\text {xvii }}$ Winter, Assessment of Wheelchair Technology in Tanzania.

${ }^{\text {xviii }}$ Homepage. Wheelchair Foundation

${ }^{\text {xix }}$ Conversations with Barbera Reading-Jones and colleagues, Tanzania Big Game Safari, P.O. Box 2458, Arusha, TZ.

${ }^{x x}$ Conversations with Basil Luwemba, Equal Opportunities for All Trust Fund (EOTF), 15 Luthuli Rd, P.O. Box 78262, Dar es Salaam, TZ.

xxi Conversations with Paula Gremley, A Beacon for the Disabled (Mwangaza Kwa Wenye Ulemavu), P.O. Box 573, Arusha, TZ.

${ }^{x x i i}$ Conversations with Maghallen Shangay, Monduli Handicapped Rehabilitation Center, P.O. Box 3044, Arusha, $\mathrm{TZ}$.

xxiii Conversations with Sophia Moshi, Usa River Rehabilitation and Training Center, P.O. Box 47, Usa-RiverArusha, TZ. 